University of Nebraska - Lincoln

DigitalCommons@University of Nebraska - Lincoln

2012

\title{
Magnetism and structure of anatase (Ti1-xVx)02 films
}

\author{
Damien Le Roy \\ University of Nebraska-Lincoln, damien.le-roy@grenoble.cnrs.fr \\ Shah R. Valloppilly \\ University of Nebraska-Lincoln, svalloppilly2@unl.edu \\ Ralph Skomski \\ University of Nebraska at Lincoln, rskomski2@unl.edu \\ Sy-Hwang Liou \\ University of Nebraska-Lincoln, sliou@unl.edu \\ David J. Sellmyer \\ NCMN, dsellmyer@unl.edu
}

Follow this and additional works at: https://digitalcommons.unl.edu/physicssellmyer

Le Roy, Damien; Valloppilly, Shah R.; Skomski, Ralph; Liou, Sy-Hwang; and Sellmyer, David J., "Magnetism and structure of anatase (Ti1-xVx)O2 films" (2012). David Sellmyer Publications. 242.

https://digitalcommons.unl.edu/physicssellmyer/242

This Article is brought to you for free and open access by the Research Papers in Physics and Astronomy at DigitalCommons@University of Nebraska - Lincoln. It has been accepted for inclusion in David Sellmyer Publications by an authorized administrator of DigitalCommons@University of Nebraska - Lincoln. 


\title{
Magnetism and structure of anatase $\left(\mathrm{Ti}_{1-\mathrm{x}} \mathrm{V}_{\mathrm{x}}\right) \mathrm{O}_{\mathbf{2}}$ films
}

\author{
D. Le Roy, ${ }^{1,2, a)}$ S. Valloppilly, ${ }^{2}$ R. Skomski, ${ }^{1,2}$ S.-H. Liou, ${ }^{1,2}$ and D. J. Sellmyer ${ }^{1,2}$ \\ ${ }^{1}$ Department of Physics and Astronomy, University of Nebraska, Lincoln, Nebraska 68588, USA \\ ${ }^{2}$ Nebraska Center for Materials Nanoscience, University of Nebraska, Lincoln, Nebraska 68588, USA
}

(Presented 31 October 2011; received 23 September 2011; accepted 12 December 2011; published online 12 March 2012)

\begin{abstract}
Anatase $\mathrm{TiO}_{2}$ is known as a promising host material for a wide-gap ferromagnetic semiconductor as it is a good solvent for numerous transition-metal elements. We report on the structural and magnetic properties of epitaxially grown anatase $\left(\mathrm{Ti}_{1-x} \mathrm{~V}_{x}\right) \mathrm{O}_{2}$ layers where $x$ covers the whole range of solubility of $\mathrm{V}$ atoms in anatase $\mathrm{TiO}_{2}$ and beyond the solubility limit of $21 \%$. We measured an average magnetic moment per vanadium as high as $1 \mu_{\mathrm{B}}$ with a magnetic percolation threshold of less than $6 \%$ which agrees with recent theoretical predictions. Interestingly, our results show a decrease of the average $\mathrm{V}$ magnetic moment as $x$ increases throughout the solubility range. Anatase $\left(\mathrm{Ti}_{1-x} \mathrm{~V}_{x}\right) \mathrm{O}_{2}$ is no longer present beyond the solubility limit, where the nonmagnetic $\mathrm{VO}_{2}$ phase forms and destroys the net magnetization. (C) 2012 American Institute of Physics. [doi:10.1063/1.3679434]
\end{abstract}

\section{INTRODUCTION}

Carrier-mediated ferromagnetism ${ }^{1}$ has attracted significant attention during the past decade as it could enable the fabrication of room-temperature ferromagnetic (FM) semiconductors by doping nonmagnetic semiconductors with transition-metal (TM) elements. However, it has turned out that it is a challenging experimental problem, especially to unambiguously exclude the presence of a secondary phase. In TM-doped oxides, unique features like the orbitalmoment anisotropy were revealed ${ }^{2}$ but the origin of roomtemperature ferromagnetism remains highly controversial and the lattice defects are found to play a key role. ${ }^{3,4}$ In particular, an indirect double exchange via oxygen vacancies $\left(v_{\mathrm{O}}\right)$ is often involved. ${ }^{5}$ Nevertheless, Yamada et al. have recently given an experimental evidence of carrier-mediated ferromagnetism in anatase $\left(\mathrm{Ti}_{0.90} \mathrm{Co}_{0.10}\right) \mathrm{O}_{2}{ }^{6} \mathrm{In}$ its pure state, anatase $\mathrm{TiO}_{2}\left(a-\mathrm{TiO}_{2}\right)$ is nonmagnetic and insulating with a bandgap of $3.2 \mathrm{eV}^{7}$ It is a good solvent for numerous TM dopants and therefore considered as a potent host material for diluted magnetic semiconductors. Appropriate doping can lead to carrier densities of $10^{21} \mathrm{~cm}^{-3}$ (Refs. 8 and 9) and ferromagnetism persisting up to $400 \mathrm{~K}$ (Ref. 10). $\left(\mathrm{Ti}_{1-x} \mathrm{~V}_{x}\right) \mathrm{O}_{2}$ is predicted to fulfill the requirements of a FM semiconductor as (i) the $\mathrm{V}$ atoms carry a magnetic moment of $1 \mu_{\mathrm{B}}$ when substituting for $\mathrm{Ti}$ and (ii) the large solubility of the $\mathrm{V}$ atoms in $a-\mathrm{TiO}_{2}$ of $x_{1}=0.21$ exceeds the percolation threshold of the FM interaction $x_{\mathrm{p}}$ of $0.056 .{ }^{8}$ Average magnetic moment $\left(\mu_{\mathrm{V}}\right)$ as high as $4.2 \mu_{\mathrm{B}}$ was reported and attributed to an unquenched orbital moment on the $\mathrm{V}$ sites. ${ }^{11}$ Our focus is on the magnetism of highly crystalline $a-\left(\mathrm{Ti}_{1-x} \mathrm{~V}_{x}\right) \mathrm{O}_{2}(001)$ films, obtained by sequential deposition of $\mathrm{V}$ and $\mathrm{TiO}_{2} . x$ varied from 0 to 0.31 , which exceeds the reported solubility limit $x_{1}$. Throughout the solubility range the crystal structure is only moderately affected by the V dopants. It is demon-

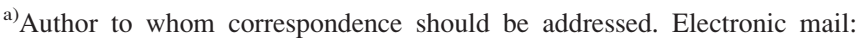
dleroy2@unl.edu.
}

strated that diluted $\mathrm{V}$ dopants induce ferromagnetism in $a-\mathrm{TiO}_{2}$, as expected for partial substitution of $\mathrm{Ti}$ by $\mathrm{V}$ with $\mu_{\mathrm{V}}$ of up to $1 \mu_{\mathrm{B}}$.

\section{EXPERIMENTAL PROCEDURES}

$a-\mathrm{TiO}_{2}\left(\mathrm{I}_{1} / \mathrm{amd}\right)$ is tetragonal with $a=0.3785 \mathrm{~nm}$ and $c=0.9514 \mathrm{~nm} .{ }^{9}$ An atomically clean and flat $\mathrm{LaAlO}_{3}(\mathrm{LAO})$ substrate is indispensable for the growth of high-quality $\mathrm{TiO}_{2}$ layers. Figures 1(a) and 1(b) show the surface morphology of the substrate. An almost perfect single-terminated surface with straight terrace edges was obtained after annealing at $1150^{\circ} \mathrm{C}$ for $2 \mathrm{~h}$ in air. The small lattice mismatch between $a-\mathrm{TiO}_{2}$ and LAO of $0.2 \%$ allows an epitaxial growth of $a-\mathrm{TiO}_{2}(001)$ on LAO (100). $a-\left(\mathrm{Ti}_{1-x} \mathrm{~V}_{x}\right) \mathrm{O}_{2}$ films were grown by pulsed laser deposition, sequentially depositing $\mathrm{TiO}_{2}$ and $\mathrm{V}$ layers. We used a $\mathrm{KrF}$ laser of $248 \mathrm{~nm}$ wavelength with pulses of $5 \mathrm{~J} / \mathrm{cm}^{2} \cdot a-\mathrm{TiO}_{2}$ was deposited from a sintered $\mathrm{TiO}_{2}$ target with $1 \mathrm{~Hz}$ pulses, under a pure $\mathrm{O}_{2}$ pressure of $1 \mathrm{mTorr}$ in order to limit the creation of $v_{\mathrm{O}}$ that are usually found to mediate the FM order. V was deposited from a pure $\mathrm{V}$ target with $15 \mathrm{~Hz}$ pulses. Deposition rates were 6 and $13 \mathrm{pm} / \mathrm{s}$, respectively. Note that $\mathrm{TiO}_{2}$ undergoes an irreversible phase transition at $577^{\circ} \mathrm{C}$ (Ref. 12) from anatase to rutile $(r-)$. Although it was observed that the heteroepitaxial growth allows the formation of anatase beyond this transition, X-ray diffraction (XRD) results showed traces of rutile in the films grown at $600{ }^{\circ} \mathrm{C}$. During the growth, the substrate temperature was $500^{\circ} \mathrm{C}$. In order to promote the diffusion of $\mathrm{V}$ atoms in the $a-\mathrm{TiO}_{2}$, the film was kept at $500{ }^{\circ} \mathrm{C}$ for $1 \mathrm{~h}$ under $1 \mathrm{mTorr}$ of pure $\mathrm{O}_{2}$. The samples were then cooled to room temperature in the same atmosphere. Figure 1(c) shows a schematic of the multilayer (ML) and the corresponding depth profile for different diffusion stages. Here we present results obtained for $a-\mathrm{TiO}_{2}(9 \mathrm{~nm}) / \mathrm{V}(2 \mathrm{~nm}) /$ $a-\mathrm{TiO}_{2}(9 \mathrm{~nm})$ and $\left\{\mathrm{TiO}_{2} / \mathrm{V}\right\}_{30} / \mathrm{TiO}_{2} \mathrm{MLs}$, in which the nominal thickness of $a-\mathrm{TiO}_{2}$ was set to $5 \mathrm{~nm}$ while the thickness of $\mathrm{V}$ layers varied from 0 to $0.7 \mathrm{~nm}(0 \leq x \leq 0.31)$. The 


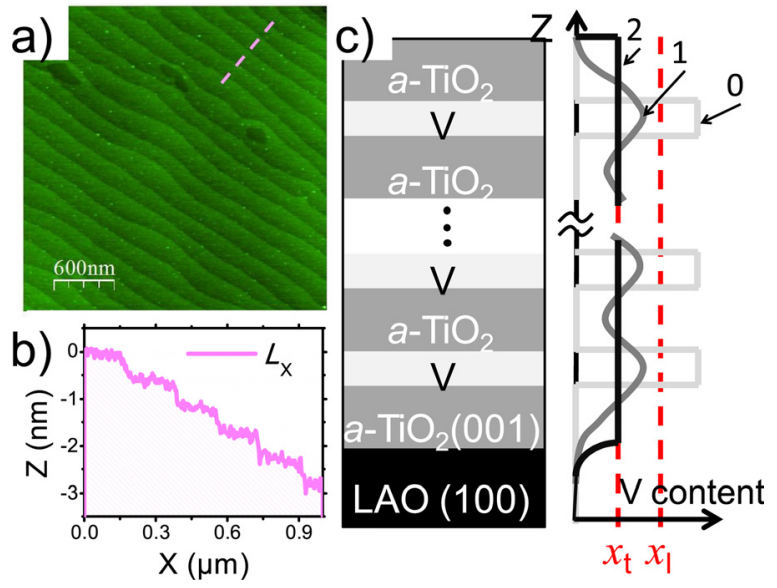

FIG. 1. (Color online) Surface morphology of the processed LAO substrate measured by AFM (a). The dashed line indicates the trace of the surface profile displayed in (b). Schematic depth profile of the ML (c) with a total V content $x_{\mathrm{t}}$ at different stages of the V-dopant diffusion process: not diffused (0), partially diffused leading to a modulated structure (1) and fully dissolved (2).

structure was analyzed by XRD with $\mathrm{Cu} K_{\alpha}$ radiation. The overall film composition was verified by energy-dispersive $\mathrm{X}$-ray spectroscopy. The magnetization was measured using a commercial superconducting quantum interference device (SQUID) magnetometer.

\section{RESULTS AND ANALYSIS}

Figure 2 shows the XRD pattern of an undoped $a-\mathrm{TiO}_{2}$ layer of $90 \mathrm{~nm}$ thickness. The only observed Braggreflections from the film are the $a-\mathrm{TiO}_{2}\{00 l\}(l=4 n, n$ an integer) lines which confirms the [001] orientation of the growth. The corresponding rocking curves have a full width at half maximum (FWHM) as small as $0.4^{\circ}$.

The question of the $\mathrm{V}$-dopant distribution is of crucial importance in order to understand the magnetic properties. A complete diffusion of the $\mathrm{V}$ dopants could be expected since the sample is kept at $500{ }^{\circ} \mathrm{C}$ during the deposition $(15 \mathrm{~h})$ and the subsequent annealing $(1 \mathrm{~h})$. Let us first consider the case of an $a-\mathrm{TiO}_{2} / \mathrm{V} / a-\mathrm{TiO}_{2}$ trilayer, where the $\mathrm{V}$ layer thickness is chosen to give an overall trilayer composition at the solubility limit of $\mathrm{V}$ in $a-\mathrm{TiO}_{2}\left(x_{\mathrm{t}}=x_{1}\right)$. A non-homogenous distribution along the growth direction would then inevitably lead to two $\mathrm{TiO}_{2}$ layers separated by an interlayer with a $\mathrm{V}$-rich phase. Figure 3 shows a $\theta-2 \theta$ scan measured on such trilayer around the $2 \theta$ position of the $a-\left(\mathrm{Ti}_{1-x} \mathrm{~V}_{x}\right) \mathrm{O}_{2}(004)$ Bragg-reflection. The presence of Laue fringes is not only the sign of a good crystallinity and flat interfaces but their period gives an accurate value of the crystallite size along

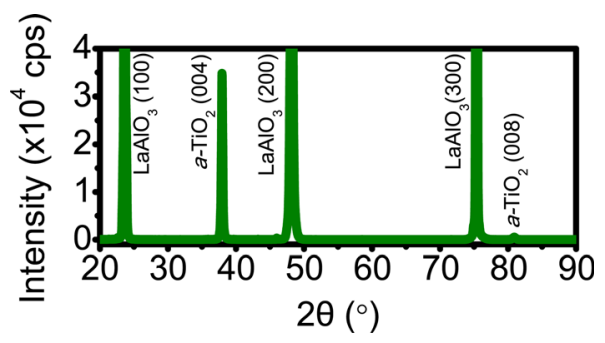

FIG. 2. (Color online) XRD pattern of an undoped $a-\mathrm{TiO}_{2}$ layer of $90 \mathrm{~nm}$.

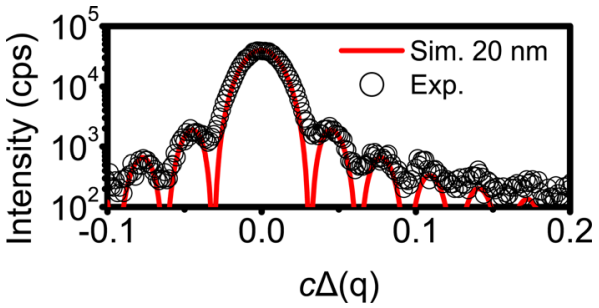

FIG. 3. (Color online) $\theta-2 \theta$ pattern around the $a-\left(\mathrm{Ti}_{1-x} \mathrm{~V}_{x}\right) \mathrm{O}_{2}(004)$ Braggreflection for a $\mathrm{TiO}_{2} / \mathrm{V} / \mathrm{TiO}_{2}$ trilayer. The solid line is the simulated pattern of a single layer of $20 \mathrm{~nm}$.

the direction perpendicular to the film plane. The period perfectly matches with the total thickness of the film which rules out the case of a subsisting V-rich interlayer. Note however that if that supports the idea of a complete diffusion of the $\mathrm{V}$ dopants and a homogenous distribution of them in the direction perpendicular to the substrate plane, it is not sufficient to discard the hypothesis of partial $\mathrm{V}$ clustering. Therefore, in the following discussion on the magnetic properties, both the homogeneous distribution and the partial clustering hypotheses are considered.

Figure 4 displays XRD patterns of $a-\left(\mathrm{Ti}_{1-x} \mathrm{~V}_{x}\right) \mathrm{O}_{2} \mathrm{ML}$ films around the $2 \theta$ position of the $a-\mathrm{TiO}_{2}(004)$ Braggreflection. The crystalline structure is only moderately affected by the $\mathrm{V}$ dopants as the FWHM of the rocking curve of $a$ - $\left(\mathrm{Ti}_{1-x} \mathrm{~V}_{x}\right) \mathrm{O}_{2}$ (004) Bragg-reflections broadened from $0.4^{\circ}$ to $0.6^{\circ}$ when $x$ increases from 0 to 0.25 , as expected for cation substitution by $\mathrm{V}^{4+}\left(\mathrm{V}_{\mathrm{Ti}}\right)$. This result agrees with earlier theoretical and experimental works showing that $\mathrm{V}$ impurities are well-dissolved in $a-\mathrm{TiO}_{2}{ }^{11,13}$

$\left(\mathrm{Ti}_{1-x} \mathrm{~V}_{x}\right) \mathrm{O}_{2}$ was found to undergo a phase modification around $x_{1}$, as the $2 \theta$ position of the most intense peak shifts from $37.7^{\circ}\left(a-\mathrm{TiO}_{2}(004)\right)$ to $39.7^{\circ}$ which matches with the position of $r-\mathrm{VO}_{2}$ (200) when $x$ increases from 0.25 to 0.31 . The $\mathrm{VO}_{2}$ phase observed at $x=0.31$ is highly crystalline and oriented with a measured rocking curve width of $0.5^{\circ}$. The presence of $\mathrm{VO}_{2}$ in this film was unambiguously confirmed by measuring the temperature dependence of the electrical resistivity between 300 and $400 \mathrm{~K}$. Indeed $\mathrm{VO}_{2}$ undergoes a metal-to-insulator transition at $338 \mathrm{~K}$ which accompanies a phase transition from high- temperature rutile $\left(\mathrm{P}_{2} / \mathrm{mnm}\right)$ to low-temperature monoclinic structure $\left(P 2_{1} / \mathrm{c}\right)$. A sharp

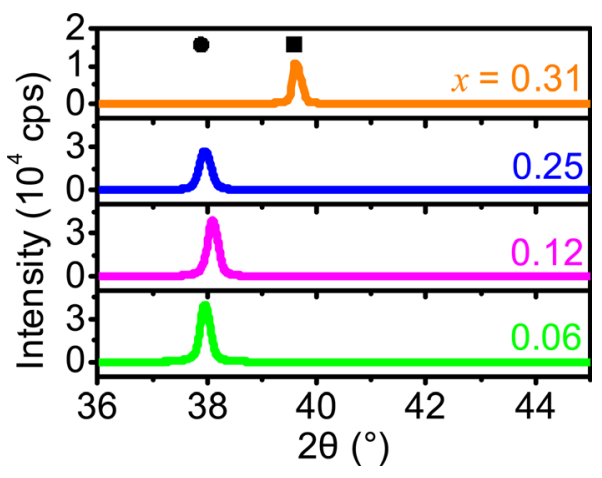

FIG. 4. (Color online) XRD pattern of $a-\left(\mathrm{Ti}_{1-x} \mathrm{~V}_{x}\right) \mathrm{O}_{2}$ films with $x$ of 0.06 , $0.12,0.25$, and 0.31 . The circle indicates the $2 \theta$ position of $a-\mathrm{TiO}_{2}(004)$ and the square the $2 \theta$ position of $r-\mathrm{VO}_{2}(200)$. 


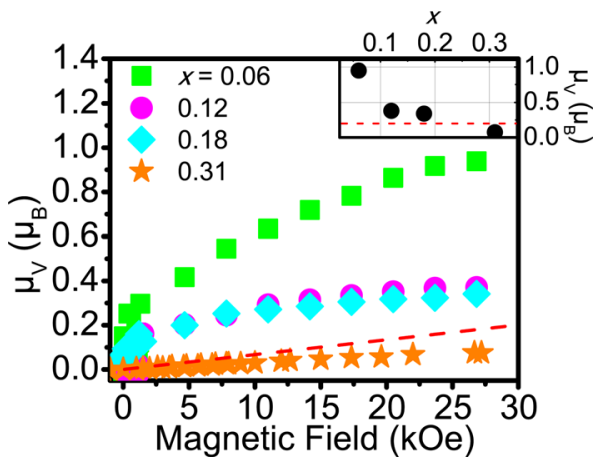

FIG. 5. (Color online) Magnetization of $\left\{\mathrm{TiO}_{2} / \mathrm{V}\right\}_{30} / \mathrm{TiO}_{2}$ MLs with $x$ of $0.06,0.12,0.18$, and 0.31 , measured at $10 \mathrm{~K}$. The inset shows the $x$ dependence of the magnetization at $3 \mathrm{~T}$. The dashed lines correspond to the calculated magnetization expected for isolated $\mathrm{V}$ atoms with a magnetic moment of $3 \mu_{\mathrm{B}}$.

decrease of the resistivity was measured at around $350 \mathrm{~K}$ in the film with $x=0.31$. No trace of pure Ti was detected by $\mathrm{XRD}$. We note that $r-\mathrm{TiO}_{2}$ and $r-\mathrm{VO}_{2}$ have similar lattice parameters. The mismatch along the in-plane directions, that is, [010] and [001] would be $0.8 \%$ and $3 \%$, respectively. The stabilized phase at $x=0.31$ values would thus correspond to $r-\left(\mathrm{Ti}_{1-x} \mathrm{~V}_{x}\right) \mathrm{O}_{2}$.

We measured negligible magnetic moment in the $\mathrm{TiO}_{2}$ film alone. In the following, we assume that the magnetic moment is carried by $\mathrm{V}$ atoms. Bulk $\mathrm{V}$ is paramagnetic and the permanent magnetic moment of vanadium is $3 \mu_{\mathrm{B}}$. The magnetization originating from isolated $\mathrm{V}$ atoms can be calculated using the Langevin function. At $10 \mathrm{~K}$ and under a magnetic field of $3 \mathrm{~T}$, it leads to $0.2 \mu_{\mathrm{B}}$ per vanadium atom.

The following magnetic measurements correspond to the $\left\{\mathrm{TiO}_{2} / \mathrm{V}\right\}_{30} / \mathrm{TiO}_{2}$ MLs. In Fig. 5 we compare the magnetization of four $\left(\mathrm{Ti}_{1-x} \mathrm{~V}_{x}\right) \mathrm{O}_{2}$ films with $x$ of $0.06,0.12,0.18$, and 0.31 . Throughout the solubility range, $\mu_{\mathrm{V}}$ remains larger than the calculated moment for isolated $\mathrm{V}$ atoms which shows that (i) the V-V pairs are magnetically coupled with $\mu_{\mathrm{V}} \approx 1 \mu_{\mathrm{B}}$ and (ii) the magnetic percolation threshold is less than 0.06 (fifth neighbor in the $a-\mathrm{TiO}_{2}$ structure). ${ }^{8}$ However, $\mu_{\mathrm{V}}$ is found to decrease when $x$ increases. According to calculations, ${ }^{13}$ a ground state with antiferromagnetic (AFM) coupling is favored for $\mathrm{V}-\mathrm{V}$ nearest neighbors and is highly sensitive to the $\mathrm{V}-\mathrm{V}$ distance, which agrees with the work of Moodera et al. ${ }^{14}$ on thin (less than 1 atomic layer thick) $\mathrm{V}$ films. On the other hand, $\mathrm{V}-\mathrm{O}-\mathrm{V}$ exchange is generally found to be FM. As the amount of $\mathrm{V}$ dopants increases, one could then expect that AFM interaction settles between the nearest $\mathrm{V}-\mathrm{V}$ pairs while FM would be favored in the other configurations. Magnetic frustration and partial AFM interaction would then lead to an overall decrease of the average $\mathrm{V}$ magnetic moment. At $x=0.25$, the $\mu_{\mathrm{V}}$ decrease would be triggered by $60 \%$ of compensated $\mathrm{V}^{4+}$ spins.

As mentioned above, we cannot exclude the hypothesis of partial V clustering. Indeed, it was previously calculated that the energy of the nearest-neighbors configuration is the lowest which favors V-dopants clustering. ${ }^{13}$ On the other hand, a theoretical work calculated that in $\mathrm{V}$ clusters, the $\mathrm{V}$ magnetic moment decreases as the cluster size increases, from $1 \mu \mathrm{B}$ (2 atoms) to $0.03 \mu \mathrm{B}$ (15 atoms). Thus, one could expect that increasing the amount of dopants $(x)$, the formation of larger $\mathrm{V}$ clusters embedded in the $a$ - $\mathrm{TiO}_{2}$ matrix leads to a decrease of the average magnetic moment.

Finally, our XRD results show that as $x$ increases beyond the solubility limit of $\mathrm{V}_{\mathrm{Ti}}$ atoms in $a$ - $\mathrm{TiO}_{2}$, the nonmagnetic $\mathrm{VO}_{2}$ phase forms that reduces the value of $\mu_{\mathrm{V}}$.

\section{CONCLUSION}

In summary, we have studied the structural and magnetic properties of highly crystalline $a-\left(\mathrm{Ti}_{1-x} \mathrm{~V}_{x}\right) \mathrm{O}_{2}$ films throughout the solubility range and beyond. Our results agree with recent calculation on an average magnetic moment of $\mathrm{V}$ atoms of $1 \mu_{\mathrm{B}}$ and a magnetic percolation threshold of less than $6 \%$. Increasing the dopant concentration is found to decrease the average $\mathrm{V}$ magnetic moment, which can be explain by (i) competing AFM and FM interaction and (ii) partial $\mathrm{V}$ clustering. Beyond the solubility limit a nonmagnetic rutile $\left(\mathrm{Ti}_{1-x} \mathrm{~V}_{x}\right) \mathrm{O}_{2}$ phase forms which leads to a negligible magnetization.

\section{ACKNOWLEDGMENTS}

This work is supported by the U.S. Army Research Office under Award No. W911 NF-09- 20039 (D.LR, D.J.S, S.V.), the National Science Foundation Materials Science and Engineering Center under Award No. DMR-0820521 (R.S., S.H.L.), and the Nebraska Center for Materials and Nanoscience (Central Facility support).

${ }^{1}$ T. Dietl et al., Science 11, 1019 (2000).

${ }^{2}$ J. Zhang et al., Phys. Rev. B 75, 214417 (2007).

${ }^{3}$ Q.-Y. Wen et al., J. Phys. D: Appl. Phys. 42, 055012 (2009).

${ }^{4}$ J.M.D. Coey et al., MRS Bull. 33, 1053 (2008).

${ }^{5}$ T. S. Herng et al., Phys. Rev. Lett. 105, 207201 (2010).

${ }^{6}$ Y. Yamada et al., Science 332, 1065 (2011).

${ }^{7}$ B.-S. Jeong et al., Solid-State Electron. 47, 2275 (2003).

${ }^{8}$ J. Osorio-Guillén et al., Phys. Rev. Lett. 100, 036601 (2008).

${ }^{9}$ Y. Furubayashi et al., Appl. Phys. Lett. 86, 252101 (2005).

${ }^{10}$ Y. Matsumoto et al., Science 291, 854 (2001).

${ }^{11}$ N. H. Hong et al., Appl. Phys. Lett. 84, 2602 (2004).

${ }^{12}$ J. Zhang et al., J. Phys. Chem. B 104, 3481 (2000).

${ }^{13}$ X. Du et al., Phys. Rev. B 74, 233201 (2006).

${ }^{14}$ J. S. Moodera et al., Phys. Rev. B 40, 8541 (1989). 